\title{
Produção de biomassa de erva-cidreira [Lippia alba (Mill.) N.E.Br.] sob adubação com composto de capim elefante inoculado e sem inoculação de actinomicetos
}

\author{
GAMA, E.V.G. ${ }^{1}$; GARRIDO, M.S. ${ }^{2}$; SILVA, F. ${ }^{1 *}$; SOARES, A.C.F. ${ }^{1}$; MARQUES, C.T.S. ${ }^{1}$ \\ ${ }^{1}$ Centro de Ciências Agrárias, Ambientais e Biológicas, Universidade Federal do Recôncavo da Bahia / UFRB, \\ Campus de Cruz das Almas, CEP: 44.380-000, Cruz das Almas-Brasil ${ }^{2}$ Universidade Federal do Vale do São \\ Francisco / UNIVASF erastovsg@yahoo.com.br; *franceli.silva@gmail.com
}

\begin{abstract}
RESUMO: A erva-cidreira [Lippia alba (Mill.) N. E. Br.] é uma espécie da família Verbenaceae amplamente utilizada pela população brasileira, devido às propriedades calmante, espasmolítica suave, analgésica, sedativa, ansiolítica e levemente expectorante. Para implantação do experimento foi produzido composto orgânico de capim elefante + esterco, na proporção de $70 \%$ de material vegetal e $30 \%$ de esterco, sem inoculação e inoculados com os isolados de actinomicetos do gênero Streptomyces: AC16; AC26; AC92 e AC103. Os compostos foram acondicionados em sacos de polietileno contendo $10,0 \mathrm{~kg}$ de solo adicionados na proporção equivalente a $20 \mathrm{t} \mathrm{ha}^{-1} \mathrm{e}$ foram reaplicados logo após a primeira colheita. As colheitas da parte aérea foram realizadas aos 75 e 165 dias após o transplante. As raízes foram colhidas logo após a segunda colheita. Os tratatamentos com adubação orgânica promoveram aumento médio na produção de biomassa da erva-cidreira de 184, 83, 125, 115 e 122\% para biomassa seca da parte aérea (MSPA) na primeira colheita, de MSPA na segunda colheita, biomassa seca total da parte aérea (MSTPA), biomassa seca de raiz (MSR) e biomassa seca total da cultura (MST), respectivamente, quando comparados com o tratamento controle, porém não houve efeito da inoculação de actinomicetos no composto orgânico. Nas condições em que este estudo foi realizado foi possível concluir que a adubação com composto orgânico de capim elefante influenciou positivamente a produção de biomassa seca da $L$. alba, mas a inoculação dos compostos com actinomicetos não exerceu influência.
\end{abstract}

Palavras-chave: plantas medicinais, compostagem, Streptomyces

\begin{abstract}
Biomass production of Lippia alba (Mill.) N.E.Br. under fertilization with compost inoculated elephant grass and without inoculation of actinomycetes. $L$. alba is a species of the family Verbenaceae widely used by the Brazilian population, because of the soothing, gentle antispasmodic, analgesic, expectorant, sedative, anxiolytic and smoothly. For the implementation of the experiment produced organic compound of elephant grass (Pennisetum purpureum Shum.) + manure at $70 \%$ plant material and $30 \%$ manure, uninoculated and inoculated with the actinomycete Streptomyces genus, AC16, AC26, AC92 and AC103. The compounds were placed in polyethylene bags containing $10.0 \mathrm{~kg}$ of soil added in a proportion equivalent to 20 $\mathrm{t} \mathrm{ha}^{-1}$ and re-apply after the first harvest. The harvests of the shoots were taken at 75 and 165 days after transplantation. The roots were harvested after the second harvest. Dealing with organic fertilization promoted the average increase in biomass production of lemon grass 184, 83, 125 , 115 and $122 \%$ for the dry stem biomass (MSPA) in the first harvest, second harvest of MSPA, total shoot biomass (MSTPA), dry biomass of the root (MSR) and the total crop biomass (MST), respectively, compared with the control, but no effect of inoculation of actinomycetes in compost. Under the conditions of this study was conducted, it was concluded that the organic compound fertilizer with elephant grass positively influenced the production of dry biomass of $L$. alba, but the injection of the compounds of the actinomycetes, without influence.
\end{abstract}

Key words: medicinal plants, composting, Streptomyces

Recebido para publicação: setembro de 2011

Aceito para publicação: março de 2012

Rev. Bras. Pl. Med., Botucatu, v.14, n.esp., p.163-168, 2012. 


\section{INTRODUÇÃO}

A erva-cidreira [Lippia alba (Mill.) N. E. Br.] é uma espécie da família Verbenaceae amplamente utilizada pela população brasileira, devido às propriedades calmante, espasmolítica suave, analgésica, sedativa, ansiolítica e levemente expectorante (Ming, 1992; Lorenzi \& Mattos, 2008).

No cultivo de $L$. alba, assim como no cultivo de culturas agrícolas o uso de fertilizantes orgânicos como fonte principal de adubação pode promover considerável aumento no crescimento das plantas em conseqüência de melhorias nas propriedades físicas e químicas do solo (Santos \& Innecco, 2004). Além disso, a adubação orgânica, é recomendada para plantas medicinais e aromáticas visando produtos em quantidade e qualidade, com segurança para a saúde humana, animal e do meio ambinte (Al-Fraihat et al., 2011).

O composto é o resultado de um processo controlado de decomposição bioquímica de materiais orgânicos (animais e vegetais), transformados em um produto mais estável e utilizado como fertilizante (Kiehl, 1985). A esse processo dá-se o nome de compostagem (Kiehl, 2004). O capim elefante (Pennisetum purpureum Schum.) se destaca para a produção de composto orgânico, porque é uma das gramíneas mais difundidas em todas as regiões tropicais e subtropicais do mundo, além disso produz elevada quantidade de biomassa seca, chegando até 80 toneladas por hectare por ano (Italiano et al., 2006).

A prática da compostagem tem sido utilizada há muitos anos em todo o mundo, é a técnica que foi idealizada para se obter mais rapidamente possível e em melhores condições a estabilização da matéria orgânica (Kiehl, 1985).

Diversos trabalhos mostram que a utilização de composto orgânico nas adubações produz múltiplos efeitos sobre o solo e as plantas cultivadas, através do aumento da permeabilidade do solo, agregação das partículas minerais, fornecimento de macro e micronutrientes, correção de acidez, incremento na população de microrganismos e elevação da eficiência na absorção de nutrientes (Kiehl, 1985; Peixoto, 2005).

Em plantas medicinais, especialmente para L. alba, buscou-se nas últimas décadas estabelecer técnicas apropriadas a fim de possibilitar a produção de matéria prima vegetal de boa qualidade, destacando-se os estudos realizados por Ming (1994), Stefanini et al. (2002), Atti-Serafini et al. (2002), Castro et al. (2002), Duarte et al. (2002), Montanari et al. (2004), Santos \& Innecco (2004), Yamamoto (2006), Camêlo et al. (2007), Morais (2009), Tavares (2009), Teles (2010) e Camêlo (2010).

O interesse nos estudos com os actinomicetos tem aumentado devido ao seu potencial em produzir grande variedade de metabólitos secundários, dentre eles antibióticos e enzimas extracelulares (Korn-Wendisch \& Kutzer, 1992). Estes microrganismos desempenham importante papel na compostagem por efetuarem a decomposição de moléculas orgânicas de certa complexidade, de peso molecular elevado, como proteínas, graxas, ceras, parafina, cutinas e quitinas, estas últimas encontradas nos resíduos animais (Crawford, 1988; Oudouch et al., 2001; Kiehl, 2008).

A inoculação e incubação de substratos orgânicos de produção de plantas com isolados de actinomicetos promove a disponibilização de nutriente e maior crescimento vegetal (Sousa et al., 2009). Porém não são encontrados na literatura trabalhos em que o uso de actnomicetos inoculados no processo de compostagem tenham sido testados para a produção de plantas medicinais.

Sendo assim, o objetivo deste trabalho foi avaliar o efeito da inoculação do composto orgânico com isolados de actinomicetos sobre a produção de biomassa de erva-cidreira.

\section{MATERIAL E MÉTODO}

O ensaio foi conduzido em casa de vegetação com delineamento experimental em blocos casualizados com seis tratamentos e quatro repetições, dando total de 24 parcelas com quatro plantas por parcela.

Os compostos orgânicos foram produzidos a partir de capim elefante + esterco em minicomposteiras (adaptado de Kiehl, 1985) na proporção de $70 \%$ de material vegetal e $30 \%$ de esterco ovino, sem inoculação e inoculados com os isolados de Streptomyces spp. AC16; AC26; AC92 e AC103 da coleção de culturas do Laboratório de Fitopatologia e Microbiologia Agrícola da UFRB, Campus Cruz das Almas. A inoculação dos isolados de Streptomyces spp. ocorreu logo após mistura e umedecimento da matéria-prima, com inoculo produzido em arroz, de acordo com Soares et al. (2007).

O processo foi controlado conforme Kiehl (1985) e aconteceu entre os dias 04 de novembro de 2009 a 04 de março de 2010, num total de 120 dias. Os teores médios de macro e micro nutrientes dos compostos orgânicos (Tabela 1) foram determinados conforme metodologia descrita por Malavolta et al. (1997) e pela EMBRAPA (1999).

Os tratamentos aplicados foram: T1: CE SI composto sem inoculação de actinomiceto; T2: CE AC16 - composto inoculado com o isolado AC16; T3: CE AC26 - composto inoculado com o isolado AC26; T4: CE AC92 - composto inoculado com o isolado AC92 e T5: CE AC103 - composto, inoculado com o isolado $A C 103$, todos adicionados na proporção de oito gramas de composto por quilograma de solo, o 
TABELA 1. Teores médios de macro e micro nutrientes dos compostos orgânicos usados na adubação Lippia alba (Mill.) N.E.Br. Cruz das Almas - BA, janeiro de 2011.

\begin{tabular}{|c|c|c|c|c|c|c|c|c|c|c|c|c|}
\hline TRAT & $\mathbf{N}$ & $\mathbf{P}$ & $\mathbf{K}$ & $\mathrm{Ca}$ & $\mathbf{S}$ & $\mathrm{Na}$ & $\mathrm{Cu}$ & $\mathrm{Fe}$ & $M n$ & B & $\mathrm{Zn}$ & C:N \\
\hline CESI & 31,4 & 4,92 & 37,75 & 19,80 & 6,26 & 5,85 & 34,01 & 1449,11 & 368,87 & 34,35 & 166,39 & $8: 1$ \\
\hline CEAC16 & 31,2 & 4,82 & 33,38 & 22,27 & 5,83 & 5,20 & 34,73 & 1352,66 & 275,03 & 33,29 & 196,48 & $9: 1$ \\
\hline CEAC26 & 31,0 & 4,17 & 38,00 & 19,10 & 5,59 & 5,73 & 34,02 & 1336,58 & 353,16 & 31,68 & 176,16 & $8: 1$ \\
\hline CEAC92 & 31,9 & 3,60 & 36,50 & 18,12 & 5,82 & 6,28 & 38,71 & 1039,93 & 359,72 & 34,91 & 163,53 & $8: 1$ \\
\hline CEAC103 & 32,9 & 3,30 & 35,63 & 16,22 & 5,41 & 5,58 & 38,45 & 916,11 & 424,48 & 49,54 & 181,77 & $8: 1$ \\
\hline
\end{tabular}

que equivale a 20 toneladas por hectare, mais o tratamento controle (T6), somente solo, sem adição de composto.

As mudas de $L$. alba foram produzidas em casa de vegetação, com estacas de aproximadamente $15 \mathrm{~cm}$ de comprimento, e com quatro folhas colocadas para enraizar em copos descartaveís de $200 \mathrm{~mL}$ contendo a mistura de terra vegetal e solo na proporção de 1:1.

As mudas de $L$. alba enraizadas foram lavadas, para remoção do substrato de enraizamento e transplantadas para sacos de polietileno com 10 $\mathrm{Kg}$ de solo, mais o tratamento adicionado. Os tratamentos foram reaplicados logo após a primeira colheita, nas mesmas proporções anteriores.

O solo usado para enchimento dos sacos foi classificado como Argilossolo Amarelo Distrocoeso (EMBRAPA, 2006) e suas características químicas, determinadas conforme Embrapa, 1999, são: matéria orgânica - 10,86 $\mathrm{g} \mathrm{Kg}^{-1} ; \mathrm{pH}\left(\mathrm{H}_{2} \mathrm{O}\right)$ - 5,8; P - $10 \mathrm{mg} \mathrm{dm}^{-3}$; $\mathrm{K}-0,1, \mathrm{Ca}-0,9, \mathrm{Mg}-0,6, \mathrm{Al}-0, \mathrm{H}+\mathrm{Al} 1,76, \mathrm{SB}-$ 1,63, CTC - 3,39 $\mathrm{Cmol} \mathrm{dm}^{-3}$ e V(\%) - 48.

As colheitas da parte aérea das plantas foram realizadas a uma altura de $15 \mathrm{~cm}$ do solo aos 75 e 165 dias após o transplante, respectivamente. Logo após a colheita as plantas foram separadas em caule e folha. Após a segunda colheita da parte aérea as raízes foram lavadas em água corrente.

Sub amostras de folhas, caule e raízes foram levadas a estufa de circulação forçada a $65^{\circ} \mathrm{C}$ até massa constante para determinação da biomassa seca de folhas (MSF), biomassa seca de caule (MSC) e biomassa seca de raízes (MSR) respectivamente, de acordo com Malavolta et al. (1997).

A biomassa seca de folhas total (MSFT) foi obtida a partir da soma da MSF do $1^{\circ}$ e e $2^{\circ}$ ciclos. A biomassa seca total da parte aérea (MSTPA) foi obtida a partir do somatório da MSFT e da biomassa seca do caule total (BSCT). A biomassa seca total (MST) foi obtida do somatório a MSTPA e da MSR.

Os dados foram submetidos à análise de variância e as médias ao teste de Scott \& Knott (1974), ao nível de $5 \%$ de probabilidade (Banzatto \& Kronka, 2006). As análises foram realizadas pelo programa computacional SISVAR - Sistema para Análise de Variância (Ferreira, 2000).

\section{RESULTADO E DISCUSSÃO}

Os resultados apresentados na Tabela 2 mostram que os tratamentos adubados com composto obtiveram produção média $184,83,125$, 115 e $122 \%$ maior de biomassa seca da parte aérea (MSPA) na primeira colheita, de MSPA na segunda colheita, biomassa seca total da parte aérea (MSTPA), biomassa seca de raiz (MSR) e biomassa seca total da cultura (MST), respectivamente, quando comparados com o tratamento controle, porém não houve efeito da inoculação de actinomicetos no composto orgânico. Maiores produções de biomassa já eram esperadas por conta do incremento na disponibilidade de nutrientes no solo causado pela adição do composto orgânico, pois de acordo com Kiehl (2008), a matéria orgânica tem marcante influência em quase todas as características e propriedades do solo, atuando na sua fertilidade e na produtividade das culturas.

Dados semelhantes foram encontrados por Ming (1994) trabalhando com a adubação orgânica (0, 1, 2, 4, $8 \mathrm{~kg} \mathrm{~m}^{-2}$ de esterco bovino), também em L. alba, o autor verificou que o aumento das doses resultou em maior rendimento de biomassa. Esses resultados diferem dos de Santos \& Innecco (2004) em que a adubação orgânica não influenciou significativamente a produção de biomassa na mesma espécie.

O efeito de adubos orgânicos pode ser verificado na produção de biomassa de outras espécies vegetais, de uso medicinal, como no estudo de Santos et al. (2009) testando o efeito de doses (0, $30.000,60.000$ e $90.000 \mathrm{~L} \mathrm{ha}^{-1}$ ) de biofertilizante e esterco bovino no cultivo de Melissa officinalis L. relata que as plantas tiveram desenvolvimento e produtividade em reposta à adubação orgânica, além de efeito crescente do rendimento de óleo essencial em função das doses de esterco bovino. Corrêa et al. (2010) testando adubação orgânica na produção de biomassa de plantas de orégano (Origanum vulgare 
TABELA 2. Produção de biomassa seca da parte aérea (MSPA) para a 1a e $2^{a}$ colheitas, biomassa seca total da parte aérea (MSTPA), biomassa seca de parte aérea (MSPA), biomassa seca de raiz (MSR) e biomassa seca total (MST) de Lippia alba (Mill) N.E.Br. sob adubação com compostos orgânicos, formulados com capim elefante (CE) mais esterco na proporção de 7:3, sem inoculação (SI) e inoculados com os isolados de actinomicetos AC16, AC26, AC92 e AC103, em dois ciclos de cultivo. Cruz das Almas - BA, janeiro de 2011.

\begin{tabular}{lccccc}
\hline TRAT & $\begin{array}{c}\text { MSPA } \\
\text { 1a Colheita }\end{array}$ & $\begin{array}{c}\text { MSPA } \\
\text { 2a Colheita }\end{array}$ & MSTPA & MSR & MST \\
\cline { 2 - 5 } CE SI & $80,71 \mathrm{a}$ & $65,98 \mathrm{a}$ & $188,47 \mathrm{a}$ & $59,29 \mathrm{a}$ & $247,76 \mathrm{a}$ \\
CE AC16 & $83,02 \mathrm{a}$ & $71,41 \mathrm{a}$ & $195,40 \mathrm{a}$ & $56,35 \mathrm{a}$ & $251,74 \mathrm{a}$ \\
CE AC26 & $80,59 \mathrm{a}$ & $65,47 \mathrm{a}$ & $187,13 \mathrm{a}$ & $51,25 \mathrm{a}$ & $238,38 \mathrm{a}$ \\
CE AC92 & $95,40 \mathrm{a}$ & $77,91 \mathrm{a}$ & $218,54 \mathrm{a}$ & $65,04 \mathrm{a}$ & $283,58 \mathrm{a}$ \\
CE AC103 & $97,72 \mathrm{a}$ & $78,49 \mathrm{a}$ & $223,31 \mathrm{a}$ & $66,54 \mathrm{a}$ & $289,85 \mathrm{a}$ \\
CONTROLE & $30,79 \mathrm{~b}$ & $39,19 \mathrm{~b}$ & $90,20 \mathrm{~b}$ & $27,73 \mathrm{~b}$ & $117,93 \mathrm{~b}$ \\
Média & 78,04 & 66,41 & 183,84 & 54,37 & 238,21 \\
CV(\%) & 25,45 & 11,58 & 16,12 & 22,76 & 17,05 \\
\hline
\end{tabular}

As médias seguidas da mesma letra na coluna não diferem entre - si pelo teste de Scott Knott, a 5\% de probabilidade.

L.) em cultivo protegido verificou que tanto a adubação com esterco bovino quanto com esterco avícola obtiveram resultados significativos para a produção de biomassa de folhas, caule, raiz, inflorescência e total.

Benedetti et al. (2009) verificaram que tratamentos com adubação orgânica obtiveram maiores produções de biomassa seca de caule, folha, raiz e parte aérea de espinheira santa [Maytenus ilicifolia (Schrad.) Planch.] em comparação ao sem adubação independente da realização de calagem no solo.

Al-Fraihat et al. (2011) concluíram que a influência da adubação orgânica sobre o acúmulo de biomassa seca de plantas medicinais é atribuído ao aumento na altura das plantas, número de ramos por planta e peso fresco da planta proporcionado por essa prática.

Estudos realizados por Maia et al. (2004), em que avaliaram a influência da adubação orgânica e mineral no crescimento de Hyptis suaveolens (L.) Poit., constatando que os maiores acúmulos de biomassa seca de folha foram obtidos com a aplicação de esterco de aves ( 45 e $80 \mathrm{~g}$ ), e os menores foram da testemunha (3 e $13 \mathrm{~g}$ ). Em hortelã japonesa (Mentha arvensis L. var. piperancens Moor), o uso de $6 \mathrm{~kg} \mathrm{~m}^{-2}$ de esterco bovino resultou na maior produção de massa seca de parte aérea $\left(4,74\right.$ tha $\left.^{-1}\right)$ das plantas, em relação à testemunha ( $\left.3,55 \mathrm{t} \mathrm{ha}^{-1}\right)$; no entanto, 0 uso de $8 \mathrm{~kg} \mathrm{~m}^{-2}$ resultou em produção semelhante às de 0,2 e $4 \mathrm{~kg} \mathrm{~m}^{-2}$ (Chaves, 2001).

Ainda relacionado o efeito da adubação com o composto orgânico e o efeito dos actinomicetos na biomassa da $L$. alba, verificou-se que todos os tratamentos com adubação orgânica tiveram redução na produção de biomassa da parte aérea do primeiro para o segundo ciclo. Esta redução variou de 13,98\% (CE AC16) a 19,67\% (CE AC103), comportamento diferente do apresentado pelo tratamento controle que aumentou $27,28 \%$ a produção de biomassa seca da parte aérea do segundo ciclo, em relação ao primeiro (Tabela 2). Esses resultados diferem dos encontrados por Santos \& Innecco (2004) para a mesma espécie, testando altura de corte e adubação orgânica em $L$. alba, onde a produção de biomassa e óleo foi superior na segunda colheita. Também dos resultados encontrados por Souza et al. (2010), avaliando a correção de solo e aplicação de esterco de curral curtido na produção de cidrão (Lippia citriodora Kunth) obtiveram produções de biomassa superiores na segunda colheita nos tratamentos com esterco e inferiores nos tratamentos só com corretivos.

Quanto à inoculação ou não dos compostos não se percebeu com este trabalho efeito dos actinomicetos inoculados no composto orgânico de capim elefante sob a produção de biomassa da $L$. alba, se faz necessário então, destacar que, não foram encontrados na literatura trabalhos que actinomicetos são inoculados em compostos orgânicos para adubação de plantas medicinais, porém estudos com a inoculação em solo e substrato já mostrou o potencial dos actinomicetos em culturas agrícolas como os trabalhos realizados por Barreto (2007) em que os isolados AC 103 e AC 26, quando incubados em substratos, promoveram incrementos significativos na altura do lançamento de mudas de cacaueiro em 117,7 e 68,3\%, respectivamente, quando comparados com a testemunha e Sousa et al. (2009) que testaram os isolados AC26, AC29, AC92 e AC103 inoculados e incubados em substratos orgânicos para produção de mudas de tomateiro, os quais demonstraram incrementos significativos, com valores entre 96,9 e $165 \%$ na altura das plantas e entre 31,6 e $51,3 \%$ na matéria seca das raízes.

Nas condições em que este estudo foi realizado foi possível concluir que a adubação com 
composto orgânico de capim elefante influenciou positivamente a produção de biomassa seca da $L$. alba, mas a inoculação dos compostos com actinomicetos não exerceu influência.

\section{AGRADECIMENTO}

Os autores agradecem a Coordenação de Aperfeiçoamento de Pessoal de Nível Superior CAPES, pela concessão da bolsa de mestrado acadêmico.

\section{REFERÊNCIA}

AL- FRAIHAT, A.H. et al. Effect of organic and biofertilizers on growth, herb yield and volatile oil of marjoram plant grown in Ajloun region, Jordan. Journal of Medicinal Plants Research, v.5, n.13, p.2822-33, 2011.

ATTI-SERAFINI, L. et al. Variation in essential oil yield and composition of Lippia alba (Mill.) N.E.Br. grown in southern Brazil. Revista Brasileira de Plantas Medicinais, v.4, n.2, p.72-4, 2002.

BANZATTO, D.A.; KRONKA, S.N. Experimentação agrícola. 4.ed. Jaboticabal: FUNEP, 2006. 237p.

BARRETO, T.R. Densidade populacional, diversidade genética e atividade de promoção de crescimento de actinomicetos associados à rizosfera de cacaueiro. 2007. 56p. Dissertação (Mestrado em Ciências Agrárias) Centro de Ciências Agrárias, Ambientais e Biológicas, Universidade Federal do Recôncavo da Bahia, Cruz das Almas.

BENEDETTI, E.L. et al. Calagem e adubação no crescimento de espinheira-santa [Maytenus ilicifolia (Schrad.) Planch.] em casa de vegetação. Revista Brasileira de Plantas Medicinais, v.11, n.3, p.269-76, 2009.

CAMÊLO, L.C.A. Caracterização de germoplasma e sazonalidade em erva-cidreira-brasileira [Lippia alba (Mill.) N. E. Br.]. 2010. 70p. Dissertação (Mestrado em Agroecossistemas) - Universidade Federal de Sergipe, São Cristóvão.

CAMÊLO, L.C.A. et al. Avaliação do comportamento de acessos de erva-cidreira-brasileira colhidos em duas épocas. Horticultura Brasileira, v.25, n.1, p.1-4, 2007. CASTRO, D.M.; MING, L.C.; MARQUES, M.O.M. Chemical composition of the essential oils of Lippia alba (Mill.) N.E.Br. at different times of harvest and different parts of branches. Revista Brasileira de Plantas Medicinais, v.4, n.2, p.75-9. 2002.

CHAVES, F.C.M. Produção de biomassa, rendimento e composição de óleo essencial de alfavaca-cravo (Ocimum gratissimum L.) em função da adubação orgânica e épocas de corte. 2001. 153p. Tese (Doutorado em Agronomia - área de concentração: Horticultura) - Faculdade de Ciências Agronômicas, UNESP, Botucatu.

CORRÊA, R.M. et al. Adubação orgânica na produção de biomassa de plantas, teor e qualidade de óleo essencial de orégano (Origanum vulgare L.) em cultivo protegido. Revista Brasileira de Plantas Medicinais, v.12, n.1, p.80-
9, 2010.

CRAWFORD, D.L. et al. Isolation and characterization of actinomycete antagonist of fungal root pathogen. Applied and Environmental Microbiology, v.59, n.11, p.3899-905. 1993.

DUARTE, E.F. et al. Enraizamento de estacas de produção de biomassa de Lippia alba (Mill.) N.E.Brow (Verbenaceae). Revista Científica Eletrônica de Agronomia, v.1, n.2, 2002.

EMPRESABRASILEIRADE PESQUISAAGROPECUÁRIA - EMBRAPA. Centro Nacional de Pesquisa de Solos. Sistema Brasileiro de classificação de solos. 2.ed. Rio de Janeiro: Embrapa Solos, 2006. 306p.

EMPRESABRASILEIRADE PESQUISAAGROPECUÁRIA - EMBRAPA. Manual de análises químicas de solos, plantas e fertilizantes. Brasília: Embrapa. 1999. 370p. FERREIRA, D.F. Sistema de análises de variância para dados balanceados. Lavras: UFLA, 2000. (SISVAR 4. 1. pacote computacional).

ITALIANO, E.C.; PEREIRA, A.V.; LEDO, F.J.S. Comportamento produtivo de genótipos de Capimelefante (Pennisetum purpureum) para corte na região Meio-Norte do Brasil. Revista Científica de Produção Animal, v.8, n.2, p.47-55, 2006.

KIEHL, E.J. Adubação orgânica: 500 perguntas e respostas. Piracicaba: Editora Degaspari, 2008. 227p. KIEHL, E.J. Fertilizantes orgânicos. Piracicaba: Editora Agronômica Ceres, 1985. 482p.

KIEHL, E.J. Manual de compostagem: maturação e qualidade do composto. 4.ed. Piracicaba: Editora Degaspari, 2004. 173p.

KORN-WENDISCH, F.; KUTZNER, H.J. The family streptomicetaceae. In: BALOWS, A. et al. (Eds.). The prokaryotes. New York: Springer Verlag, 1992. 1027p.

LORENZI, H.; MATOS, F.J.A. Plantas Medicinais no Brasil: nativas e exóticas. 2.ed, Nova Odessa: Instituto Plantarum, 2008. 544p.

MAIA, S.S.S. et al. Efeito da adubação orgânica e mineral sobre o crescimento de Hyptis suaveolens (L.) Poit. em casa de vegetação Horticultura Brasileira, n.22, Supl. CD-Rom. 2004.

MALAVOLTA, E.; VITTI, G.C.; OLIVEIRA, S.A. Avaliação do estado nutricional das plantas: princípios e aplicações. 2.ed. Piracicaba: POTAFOS. 1997. 319p.

MING, L.C. Influência da adubação orgânica na produção de biomassa e óleo essencial de Lippia alba. Horticultura Brasileira, v.12, n.1, p.49-52. 1994.

MING, L.C. Influência de diferentes níveis de adubação orgânica na produção de biomassa e teor de óleos essenciais de lippia alba (Mill.)N.E.Br. Verbenaceae. 1992. 206p. Dissertação (Mestrado em Ciências Biológicas) - Universidade Federal do Paraná, Curitiba.

MONTANARI, R.M. Phenotypical plasticity of the external morphology in Lippia alba (Mill.) N. E. Br. ex Britt \& Wilson in response to level of luminosity and fertilization. Revista Brasileira de Plantas Medicinais, v.6, n.3. p.96-101, 2004.

MORAIS, L.A.S. Influência dos fatores abióticos na composição química dos óleos essenciais. Horticultura Brasileira, v.27, n.2. p.S4050-63, 2009.

OUHDOUCH, Y.; BARAKATE, M.; FINANCE, C. Actinomycetes of moroccan habitats: isolation and 
screening for antifungal activities. European Journal Soil Biology, v.37, n.1, p.69-74, 2001.

PEIXOTO, R.T.G. Compostagem: princípios, práticas e perspectivas em sistemas orgânicos de produção. In: AQUINO, A.M.; ASSIS, R.L. (Eds.). Agroecologia: princípios e técnicas para uma agricultura orgânica sustentável. Brasília: Embrapa Informações Tecnológica, 2005. p.388-422.

SANTOS, M.F. et al. Esterco bovino e biofertilizante no cultivo de erva-cidreira-verdadeira (Melissa officinalis L.). Revista Brasileira de Plantas Medicinais, v.11, n.4, p.355-9, 2009.

SANTOS, M.R.A.; INNECCO, R. Adubação orgânica e altura de corte da erva-cidreira brasileira. Horticultura Brasileira, v.22, n.2, p.182-5, 2004.

SCOTT, A.; KNOTT, M. Cluster-analysis method for grouping means in analysis of variance. Biometrics, v.30, n.3, p.507-12, 1974.

SOARES, A.C.F. et al. Production of streptomycete inoculum in sterilized rice. Scientia Agricola, v.64, n.6, p.641-4, 2007.

SOUSA, C.S.; SOARES, A.C.F.; GARRIDO, M.S. Produção de mudas de tomateiro em substrato orgânico inoculado e incubado com estreptomicetos. Bragantia, v.68, n.1, p.195-203, 2009.

SOUZA, M.F. et al. Calagem e adubação orgânica na produção de biomassa e óleo essencial em Lippia citriodora Kunth. Revista Brasileira de Plantas Medicinais, v.12, n.4, p.401-5, 2010.

STEFANINI, M.B.; RODRIGUES, S.D.; MING, L.C. Ação de fitorreguladores no crescimento da erva-cidreirabrasileira. Horticultura Brasileira, v.20, n.1, p.18-23, 2002.

TAVARES, I.B. Propagação vegetativa, adubação orgânica e idades de colheita de quimiotipos de erva-cidreira [Lippia alba (Mill.) N. E. Brown]. 2009. 85p. Dissertação (Mestrado em produção vegetal) Fundação Universidade Federal do Tocantins, Gurupi. TELES, S. Avaliação do teor e da composição química das folhas de Lippia alba (Mill) N. E. Browm. e Mentha piperita L. cultivadas em Cruz das Almas, Santo Antonio e Amargosa, submetidas às diferentes épocas de colheita e processos de secagem. 2010. 93p. Dissertação (Mestrado em Ciências Agrárias) - Centro de Ciências Agrárias, Biológicas e Ambientais, Universidade Federal do Recôncavo da Bahia, Cruz das Almas.

YAMAMOTO, P.Y. Interação genótipo $x$ ambiente na produção e composição de óleos essenciais de Lippia alba (Mill.) N.E.Br. 2006. Dissertação (Agricultura Tropical e Subtropical) - Instituto Agronômico, Universidade de São Paulo, Campinas. 